\title{
86. A New Technique for Chromosome Study of Murine Oocytes
}

\author{
By Yujiroh Kamiguchi, Kenji Funaki, and Kazuya Mikamo \\ Department of Biological Science, Asahikawa Medical College, \\ Asahikawa, Japan \\ (Communicated by Sajiro Makino, M. J. A., June 8, 1976)
}

Thanks to a simple method developed by Tarkowski (1966) for mouse chromosomes of meiotic and cleaving eggs, a considerable development has been made in karyological studies of mammalian eggs. His technique has been adopted by many authors for different purposes using various mammalian species. Chromosome analysis of gametes or early zygotes is indeed one of the most important means for searching for the etiologic factors of chromosomal anomalies, as well as for understanding their causal mechanisms. Of course, a karyological study of the eggs at these stages demands a highly reliable method for securing a proper spreading of all chromosomes, since an oocyte carries only one spindle, and a cleaving egg a limited number of metaphasic blastomeres. However, Tarkowski's technique often tends to induce loss or scattering of chromosomes, which is caused by rupture of the cell membrane either at the moment of application of fixative or during the drying process.

We describe here a new technique suitable for chromosome study in ovarian and tubal eggs of murines. Specific features of the method are first, to disperse chromosomes completely within the egg cytoplasm avoiding overlap chromosomes, and second, to flatten and dry the egg without rupturing the cell membrane, thus, preventing chromosomes from swimming away from the egg.

Description of the method. Eggs of the Chinese hamster or the mouse are collected from the ampullar region of oviducts in the morning of the day of estrum. To remove the cumulus oophorus cells, the recovered eggs are treated with $0.5 \%$ trypsin (Difco) dissolved in Dulbecco's phosphate buffer saline without calcium and magnesium for 1.5 minutes. A continuous pipetting is needed during the treatment to accelerate the action of trypsin. The trypsin treatment is also effective to weaken the zona pellucida. The denuded eggs are then treated with $30 \%$ calf serum for 60 minutes at $37^{\circ} \mathrm{C}$. This extremely long hypotonic treatment is and could analyze two

Reprints request: Prof. K. Mikamo, Department of Biological Science, Asahikawa Medical College, Asahikawa, Japan, 071-01. 

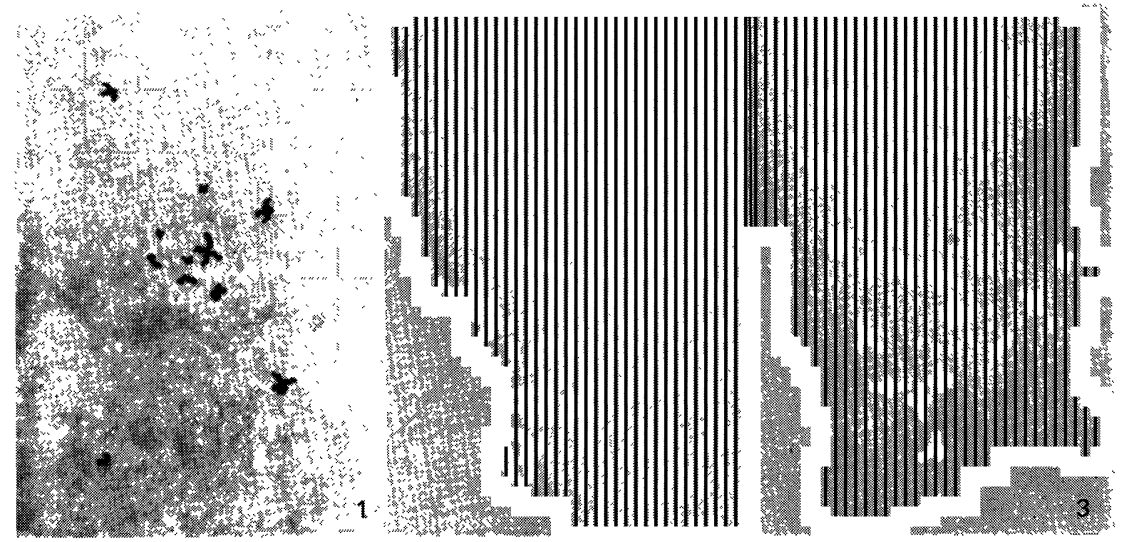

Fig. 1: Metaphase of the second meiotic division of the Chinese hamster, showing a haploid set of 11 chromosomes dispersed properly within the flattened ooplasm. Fig. 2: The first meiotic metaphase of the Chinese hamster. Fig. 3: The first meiotic metaphase of the mouse.

important to disintegrate completely the microtubules of the spindle, and eventually to disperse the chromosomes within the ooplasm.

After this treatment the eggs, together with a small amount of the hypotonic solution, are placed gently in a mixture of absolute methanol, glacial acetic acid and distilled water at a proportion of $5: 1: 4$. This solution dissolves the zona pellucida and gently fixes the eggs. Up to this step, the egg container must be replaced for every change of solution. A deep, hollow glass with a capacity of about $1 \mathrm{ml}$ (plate spot depression three, $34 \times 85 \mathrm{~mm}$, CORNING) was used in our laboratory. Throughout the procedure handling and observing of the eggs was performed under the binocular dissecting microscope. This container was found to be convenient and practical.

Five minutes after placing the eggs in the above-mentioned solution, a single egg, together with a small amount of the fixative, is sucked up into a Spemann pipette with a fine point, then pushed out within a circle which is marked on the reverse side of a grease-free slide. While the fixative spreads, the egg sticks to the slide near the tip of the pipette. The egg is re-fixed and tightly stuck there by an immediate application of a few drops of Carnoy's solution. The slide is put at once into a coplin jar filled with the same fixative and kept there for 20 minutes or more.

In the last step, the slide is dipped into a mixture of absolute methanol, glacial acetic acid and distilled water $(3: 3: 1)$ for 1 minute to help the egg flatten during the drying process. The slide is removed very slowly from the solution and dried by air which is moisturized by passing through water at $37^{\circ} \mathrm{C}$. Adequate humidity 
Table I. The rate of success in preparing 2nd meiotic chromosome slides and the incidence of chromosomal aberration in the Chinese hamster

\begin{tabular}{|c|c|c|c|c|}
\hline $\begin{array}{l}\text { No. of } \\
\text { litters }\end{array}$ & $\begin{array}{l}\text { No. of } \\
\text { C. L. } \\
\text { (mean) }\end{array}$ & $\begin{array}{l}\text { No. of eggs } \\
\text { collected } \\
(\% \text { C. L.) }\end{array}$ & $\begin{array}{l}\text { No. of eggs } \\
\text { karyotyped } \\
\text { (\% eggs collected) }\end{array}$ & $\begin{array}{l}\text { No. of chromosome } \\
\text { aberrations } \\
\text { (\% eggs analyzed) }\end{array}$ \\
\hline 69 & $\begin{array}{r}453 \\
(6.6)\end{array}$ & $\begin{array}{c}449 \\
(99.1)\end{array}$ & $\begin{array}{c}378 \\
(84.2)\end{array}$ & $\begin{array}{c}22 \\
(5.8)\end{array}$ \\
\hline
\end{tabular}

The eggs were collected from the animals in various estrous cycles including the menarcheal cycle, the lst cycle after weaning and the 5th cycle after weaning. A comparative study of these cycles with respect to the chromosome aberration will be reported elsewhere.

Table II. The rate of success in preparing chromosome slides of murine oocytes or embryos in the previous studies

\begin{tabular}{|c|c|c|c|c|c|}
\hline Authors & Animals & $\begin{array}{l}\text { Stages at } \\
\text { collection }\end{array}$ & $\begin{array}{l}\text { No. of } \\
\text { litters }\end{array}$ & $\begin{array}{c}\text { No. of } \\
\text { eggis }\end{array}$ & $\begin{array}{l}\text { No. of eggs } \\
\text { karyotyped }(\%)\end{array}$ \\
\hline Vickers (1967) & mouse & blastocyst & 16 & 223 & $115(52 \%)$ \\
\hline $\begin{array}{l}\text { McGaughey \& } \\
\text { Chang (1969) }\end{array}$ & mouse & $\begin{array}{l}\text { primary } \\
\text { oocyte }\end{array}$ & - & 148 & $82(55 \%)$ \\
\hline $\begin{array}{l}\text { Ingalls \& } \\
\text { Yamamoto (1972) }\end{array}$ & $\begin{array}{l}\text { golden } \\
\text { hamster }\end{array}$ & 4-6-cell & 56 & 634 & $299(47 \%)$ \\
\hline Donahue (1972) & mouse & 1-cell & 180 & 4885 & $338(7 \%)$ \\
\hline $\begin{array}{l}\text { Uchida (personal } \\
\text { commu.) }\end{array}$ & mouse & $\begin{array}{l}\text { secondary } \\
\text { oocyte }\end{array}$ & - & 3930 & $2203(56 \%)$ \\
\hline
\end{tabular}

in the air is essential to flatten the ooplasm uniformly. Routinely, the air-dried slides are stained with Giemsa solution.

Results. As shown in Table I, of 449 eggs collected from 69 females, 378 eggs $(84.2 \%)$ were karyotyped successfully. In these slides, the chromosomes were properly spread and maintained within the flattened ooplasm (Fig. 1).

Out of the 71 eggs (15.8\%) which were not analyzed, 5 eggs had been degenerated before collection without showing meiotic spindle. Seventeen eggs whose cell membrane broke during the process were discarded at once. The majority of these eggs were degenerative, showing various features different from normal eggs. Twenty-two eggs were lost accidentally during the preparation process. The remaining 27 eggs were unsuitable for analysis due to splitting or overlapping of the chromosomes.

With the same procedure, primary oocytes of the hamster and the mouse were also prepared satisfactorily (Figs. 2 and 3). Moreover, this method was found to be applicable, with a slight modification, to early zygotes of the hamster and the rat.

Remarks. Although Tarkowski's method has been employed in many studies of murine oocytes or early zygotes, the rates of success preparation are usually low (Table II). Mikamo and Hamaguchi (1975) developed a new chromosome technique for the rat blastocysts 
or more metaphase plates per embryo in about $70 \%$ of the preparations. In the present study, their method was largely modified for use with the secondary oocyte.

Recently, Uchida and Lee (1974) have found, with Tarkowski's method, a much higher incidence of hypohaploidy than hyperhaploidy in the X-ray irradiated mouse secondary oocytes, though they have not yet determined whether this result was ascribed to chromosomal nondisjunction or to a technical error due to an accidental loss of chromosomes during slide preparation. This sort of ambiguity can hardly be avoidable in karyologic analysis of a material with a limited number of metaphase spindles unless a new method is developed to surmount the basic technical obstacle. The present technique made it possible to prepare the chromosome slides without rupturing the egg cell membrane. The slides prepared with this method appear to be far more reliable than those made using any previous method, in respect of the spreading and the maintenance of chromosomes. This technique may be useful to investigate possible correlations between chromosomal aberrations and various teratogenic factors, such as aging of the ovum, radiation, certain chemical substances, etc.

Summary. A new technique for preparing chromosomes of murine oocytes is specially developed to obtain a proper spreading and reliable maintenance of chromosomes within the flattened dry ooplasm.

Acknowledgments. We are thankful to Emeritus Professor Dr. Sajiro Makino, Hokkaido University, for his advice and continuous encouragement. Supported by grants from the Ministry of Education and the Ministry of Health and Welfare of Japan.

\section{References}

Donahue, R. P. (1972) : Proc. Nat. Acad. Sci., 69, 74-77.

Ingalls, T. H., and Yamamoto, M. (1972) : Arch. Environ. Health, 24, 305-315. McGaughey, R. W., and Chang, M. C. (1969) : J. Exp. Zool., 170, 397-410.

Mikamo, K., and Hamaguchi, H. (1975) : in Aging Gametes (Blandau, R. J., ed.), pp. 72-97, S. Karger, Basel.

Tarkowski, A. K. (1966) : Cytogenetics; 5, 394-400.

Uchida, I. A.: Personal communication.

Uchida, I. A., and Lee, C. P. V. (1974): Nature, 250, 601-602.

Vickers, A. D. (1967) : J. Reprod. Fert., 13, 375-376. 